\title{
PRACTICE AND DISCUSSION ON LIGHTING DESIGN OF URBAN LANDSCAPE BRIDGE
}

\author{
Wenting ZHANG* and Jianjun WNAG \\ Chang'an University, Xi'an, Shaanxi, 710061, China; \\ *E-mail:209959209@qq.com
}

\begin{abstract}
The design status of an urban landscape bridge lighting system was analyzed via system analysis. Through the evaluation of eight two-level, 24 three-level, and five four-grade indexes on the basis of three aspects, namely, design process, electricity consumption calculation, and lighting effect. The hierarchy framework and index relationship of the entire system were clearly defined. Many angles reflected the links involved in the design of bridge lighting system. The neural network method was used in verifying the screening results to provide a comprehensive indicator specimen for establishing the evaluation system of the system. On the basis of the knowledge and experience of experts, information was processed, and the subjective influence and uncertainty of human calculation could then be reduced.
\end{abstract}

Keywords: urban landscape, bridge, lighting, Delphi method, ter Faye Fa screening method, neural network method

\section{INTRODUCTION}

Urbanization and urban landscape designs revolve around the city. In the past, development of bridges involved natural stone beams or plants. Trees were commonly utilized to cross rivers and streams. People used artificial bricks and rattan materials to construct passages in relatively complex environments. With the current development of technology, bridges are developed using special materials and have unique designs with strong structure. Bridges have a single traffic function but have unique structures [1]. With the development and progress of society, lighting has gradually developed from its basic to artistic and quality functions, thereby achieving high-quality vision that satisfies the functional requirements of lighting [2]. Bridges are important structures of urban traffic. These structures across urban rivers are one of the elements of a city. The river itself is also a component of a city. Numerous civilizations begin with rivers flowing to a city. For example, Nanjing on the Huaihe River from Qing Dynasty, Guangzhou on the Pearl River, and Tianjin on the Haihe River. The city centre is the key point of every city's landscape, whether daytime landscaping or night lighting landscape enhances the colour of a city [3]. The bridge on the Urban Central River is different from the city's building. Buildings in most cities are often large, and constructing enhanced buildings is possible. Developing nightscape lighting project involves many attempts with high chance of failure [4]. Therefore, evaluating the lighting engineering of urban landscape bridges is important.

\section{STATE OF THE ART}

A bridge in a city affects the urban space and the life of people. The longitudinal development of bridges in different periods reflects the changes and levels of social and urban improvements. It also denotes the development in the fields of science, technology, and aesthetics [5]. The night landscape engineering of a bridge is accompanied by the challenge of new lighting requirements due to new technolo- 
gy of structural mechanics supported by the bridge itself. Meanwhile, the progress of lighting technology and equipment also has high modification requirements. With the development of social culture, conforming to the general needs of the masses becomes difficult due to the people's increasing aesthetic standards [6]. At present, local and international research on theories and methods of bridge and bridge lighting design has achieved certain results. However, many projects in China have poor quality due to the speed of urban construction. Some of these designs are inconsistent with the development of urban planning, and the connections between the design and construction are poor because of several subjective reasons. The lighting of bridges is an important landscape of the city centre. The entire display directly affects the image of a city and the daily life of people [7]. Along with the development process of a city, a bridge night scene project should not only compete with regard to beauty but also with times; hence, constant upgrade is necessary, which requires the research and summary of the same bridge project to provide information for upgrading. The overall cost of a bridge night lighting project is large; however, sometimes the effect is not so good. The two designs involve additional manpower and material resources. Therefore, the practice and discussion of the design of urban landscape bridge lighting has practical importance.

\section{METHODOLOGY}

\subsection{Preliminary Screening of ter Faye Fa Index}

In comparison with other methods that tend to delete concepts, ter Faye Fa is a screening method with direction verification. Therefore, the preliminary screening of the electrical efficiency of the lighting system of a bridge was implemented using the Delphi method. Ter Faye Fa is a method that uses expert knowledge and experience. Experts were consulted with regard to the design of evaluation indicators and statistical processing and they provided feedback after the consultation. When the expert opinion is consistent after the poll, the final target was determined [8]. Ter Faye Fa is an internationally recognized forecasting and decision-making method for establishing a system engineering evaluation system. Anonymous method was not utilized to obtain information from an expert. The ex- perts can modify the initial feedback within a specified time. After collecting all the information, the feedback data were processed mathematically according to ter Faye Fa's criterion, and the index was initially determined. The ter Faye Fa's main criterion is described below. The expert opinion concentration degree $E$ reflects the recognition degree of the experts to the index. The feedback score of experts was provided, and the weighted average of the number of participated experts is follows:

$$
E=\frac{1}{m} \sum_{i=1}^{m} a_{i}
$$

where $m$ is the number of experts, and $a_{i}$ is the feedback score. The degree of divergence of expert opinion $\delta$ denotes the degree of divergence among experts in a certain factor and is expressed as follows:

$$
\delta^{2}=\frac{1}{\mathrm{~m}-1} \sum_{i=1}^{m}\left(a_{i}-E\right)^{2} .
$$

The restricted values of $E$ and $\delta$ can be set to $E_{0}$ and $\delta_{0}$, respectively depending on a specific problem. When equations 3 and 4 are satisfied, the index is retained.

$$
E_{1}>E_{0} \text {, }
$$

where $E_{i}$ is the concentration value obtained by using specific indicators, and $E_{0}$ is the set concentration limit value.

$$
\delta_{i}<\delta_{0}
$$

where $\delta_{i}$ is the discrete-time value obtained for a specific index, and $a$ is the set of discrete-time limits. The experts involved were four lighting design experts, two lighting experts, two pedestrians, and two bridge lighting management staff. Given that the degree of evaluation of each electricity efficiency index is relatively vague, the evaluation Table 1 of the degree of impact was set. As shown in the table, the score system does not adopt the $10 \%$ or the percentage system because it is evaluated according to the maximum or percentage system. When determining the weight ratio, the information (i.e., the number of $[0,1])$ was expressed as a percentage that needed to be normalized. Apart from the evaluation of seve- 
Table 1. Evaluation of the Influence Degree of Electric Effect

\begin{tabular}{|c|c|c|c|c|c|}
\hline $\begin{array}{c}\text { Influence } \\
\text { degree }\end{array}$ & $\begin{array}{c}\text { Not very } \\
\text { important }\end{array}$ & $\begin{array}{c}\text { Slightly } \\
\text { important }\end{array}$ & $\begin{array}{c}\text { Very } \\
\text { important }\end{array}$ & $\begin{array}{c}\text { Obviously } \\
\text { important }\end{array}$ & $\begin{array}{c}\text { Absolutely } \\
\text { important }\end{array}$ \\
\hline Score value & 0.1 & 0.3 & 0.5 & 0.7 & 0.9 \\
\hline
\end{tabular}

Table 2. Level Evaluation Parameter of the Table Method

\begin{tabular}{|l|c|c|c|c|c|c|c|c|c|c|c|c|}
\hline \multicolumn{1}{|c|}{ Expert code } & 01 & 02 & 03 & 04 & 05 & 06 & 07 & 08 & 09 & 10 & $\delta$ & $E$ \\
\hline Design process & 0.9 & 0.9 & 0.9 & 0.9 & 0.9 & 0.9 & 0.9 & 0.9 & 0.9 & 0.9 & 0 & 0.9000 \\
\hline $\begin{array}{l}\text { Electric effect } \\
\text { measurement }\end{array}$ & 0.9 & 0.5 & 0.7 & 0.9 & 0.5 & 0.9 & 0.7 & 0.9 & 0.7 & 0.7 & 0.158 & 0.7400 \\
\hline Lighting effect & 0.7 & 0.9 & 0.9 & 0.7 & 0.9 & 0.9 & 0.5 & 0.7 & 0.9 & 0.9 & 0.141 & 0.8000 \\
\hline
\end{tabular}

Table 3. Two-stage Evaluation Parameter of the Table Method

\begin{tabular}{|l|c|c|c|c|c|c|c|c|c|c|c|c|}
\hline \multicolumn{1}{|c|}{ Expert code } & 01 & 02 & 03 & 04 & 05 & 06 & 07 & 08 & 09 & 10 & $\delta$ & $E$ \\
\hline $\begin{array}{l}\text { Subway } \\
\text { characteristics }\end{array}$ & 0.3 & 0.3 & 0.3 & 0.3 & 0.3 & 0.3 & 0.9 & 0.3 & 0.5 & 0.5 & 0.114 & 0.3200 \\
\hline $\begin{array}{l}\text { Lighting } \\
\text { specification }\end{array}$ & 0.7 & 0.9 & 0.9 & 0.9 & 0.9 & 0.9 & 0.7 & 0.9 & 0.9 & 0.9 & 0.063 & 0.8800 \\
\hline $\begin{array}{l}\text { Selection of } \\
\text { lighting }\end{array}$ & 0.9 & 0.9 & 0.9 & 0.9 & 0.9 & 0.9 & 0.7 & 0.9 & 0.9 & 0.9 & 0.063 & 0.8800 \\
\hline Lighting control & 0.9 & 0.9 & 0.9 & 0.0 & 0.7 & 0.9 & 0.7 & 0.7 & 0.7 & 0.7 & 0.105 & 0.8000 \\
\hline $\begin{array}{l}\text { Illumination } \\
\text { calculation }\end{array}$ & 0.7 & 0.7 & 0.7 & 0.9 & 0.7 & 0.9 & 0.7 & 0.7 & 0.7 & 0.7 & 0.084 & 0.7400 \\
\hline $\begin{array}{l}\text { Lighting } \\
\text { consumption }\end{array}$ & 0.7 & 0.9 & 0.9 & 0.7 & 0.9 & 0.9 & 0.7 & 0.9 & 0.9 & 0.9 & 0.097 & 0.8400 \\
\hline Other losses & 0.3 & 0.5 & 0.5 & 0.5 & 0.5 & 0.7 & 0.7 & 0.5 & 0.5 & 0.5 & 0.114 & 0.5200 \\
\hline Test standard & 0.7 & 0.5 & 0.9 & 0.7 & 0.7 & 0.9 & 0.7 & 0.7 & 0.9 & 0.9 & 0.135 & 0.7600 \\
\hline
\end{tabular}

ral special indicators, describing conditions with regard to $[0,1]$ values is impossible. Hence, normalization is redundant and unnecessary.

The screening criteria of the ter Faye Fa were set. When the two bits after the decimal point were half adjusted and $E$ is greater than 0.4 , an index was assigned to the index set. Thus, the value was only used as an auxiliary reference value. When the degree of divergence is large, the information is collected again until its value reaches a small stable state. Tables $2-4$ show the expert evaluation information, $\mathrm{E}$ value, and eight values for all levels of indicators, respectively. The 10 experts were anonymous and numbered 01-10. The index at the left side of the table and the number of tables intersected by experts and numbers were scored.
Table 2 presents the evaluation value of the one-level Delphi method. The $E$ value of the three indicators is between 0.7 and 0.9 , and they show the importance of the expert opinion. The small $a$ value denotes the consensus of the experts. The design process, electrical efficiency calculation, and lighting effect are used as the evaluation index system. Table 3 depicts the evaluation value of the two-level Delphi method. Among them, the $E$ value of the seven indexes is between 0.5 and 0.9 , whereas that of the subway characteristic is 0.32 . According to the set of screening criteria, the subway characteristic index should be removed; hence, the subway characteristics are not included in the index set. Meanwhile, the corresponding statistical results of the three-level indicators will not be included. There- 


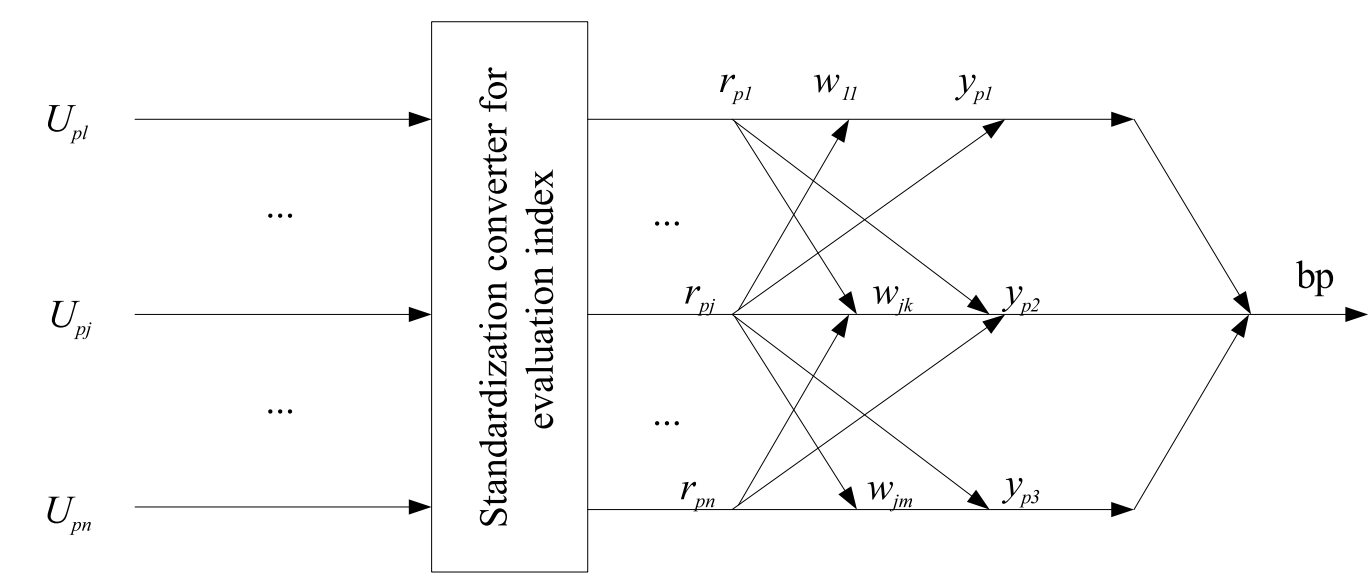

Parameter data layer Input layer Hidden layer Input layer

Fig.1. Principle diagram of the BP neural network method

fore, the lighting standard, selection, control, calculation, and consumption of lighting and other losses and verification standards are used as evaluation indicators in the second level.

Given that the lamps and lanterns are covered with additional indicators, the four-level indicators of the luminaire should be evaluated. The five indicators met the requirements and were classified into index sets. By screening the indicators using the Delphi method, three one-level, seven two-level, 20 three-level, and five four-level indicators were present.

\subsection{Index Verification Based on Neural Network Method}

The basic principle of artificial neural network is similar to that of a human brain. The BP neural network approach is used as the two-confirmation method of the index. In view of the nonlinear relationship between the indexes of the bridge lighting electric effect system, the trained neural network provides the expert evaluation idea of the network through the method of connection right. It can achieve a suitable output to the input of the non-centralized sample and can accomplish an approximation function. Moreover, the network can well simulate the quantitative evaluation of experts. Hence, subjectivity and uncertainty in the evaluation can be avoided. Fig. 1 shows the diagram of the principle of BP neural network.

$n$ represents the input node (i.e., the number of evaluation indicators), $m$ denotes the number of hidden nodes, and $\mathrm{U}_{p 1}, \mathrm{U}_{p 2}, \ldots, \mathrm{U}_{p n}$ is the evaluation index value of the $\mathrm{P}$ sample model on the
$X=\left\{x_{1}, x_{2}, \ldots, x_{n}\right\}$ of the evaluation index, remember $\bar{U}_{\mathrm{P}}$. The formula is as follows:

$$
\overline{\mathrm{U}}_{\mathrm{P}}=\left\{\overline{\mathrm{U}}_{\mathrm{P} 1}, \overline{\mathrm{U}}_{\mathrm{P} 2}, \ldots, \overline{\mathrm{U}}_{\mathrm{Pn}}\right\}^{\mathrm{T}}=\left(\overline{\mathrm{U}}_{\mathrm{Pj}}\right)_{\mathrm{h} \times \mathrm{n}},
$$

where $r_{p 1}, r_{p 2}, \ldots, r_{p n}$ is the evaluation vector $\bar{r} p$ after quantizing the standard converter of $X$ upper body, which can be expressed as follows:

$$
\bar{r} p=\left\{\mathrm{r}_{\mathrm{p} 1}, \mathrm{r}_{\mathrm{p} 2}, \ldots, \mathrm{r}_{\mathrm{pn}}\right\},
$$

where $w_{j k}(j=1,2, \ldots, n ; k=1,2, \ldots, m)$ is the connection weight between the first nodes of the input layer and the $k$ node of the hidden layer, $y_{p k}(k=1,2, \ldots, m)$ is the output of the hidden layer ( $k$ node) of sample mode $P, w_{k}(k=1,2, \ldots, m)$ is the connection weight between the $k$ node and its output layer, and BP is the output of sample pattern $P$. The algorithm of the BP neural network evaluation was described using the sigmoid function, which is expressed as follows:

$$
f(x)=(1+\exp (-x))^{-1}
$$

The output $y_{p k}$ of the hidden layer sample pattern $P$ is calculated as:

$$
y_{p k}=f\left(\sum_{j=1}^{n} w_{j k} r_{p j}-\theta_{k}\right)
$$

where $k=1,2, \ldots, m ; \theta_{k}$ represents the bias value of the hidden layer ( $k$ node). The output $b_{p}{ }_{p}$ of the output layer sample pattern $P$ is calculated as:

$$
b_{p}=f\left(\sum_{k=1}^{m} w_{k} y_{p k}-\theta\right),
$$


Fig.2. Subordinate function of the fuzzy controller

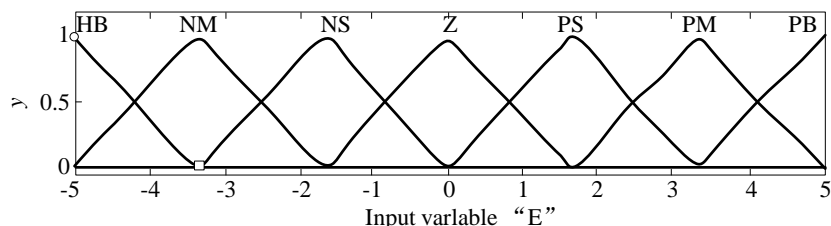

(a) The membership function of illuminance deviation $\mathrm{E}$

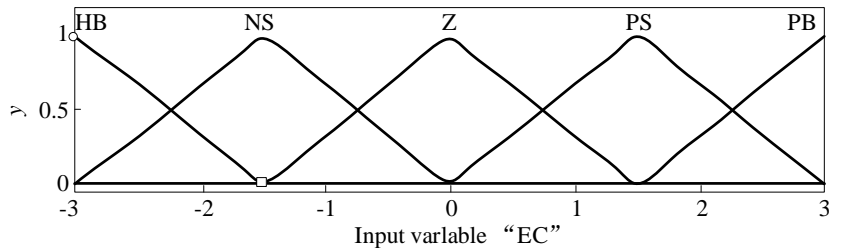

(b) The membership function of the variation rate of illuminance EC

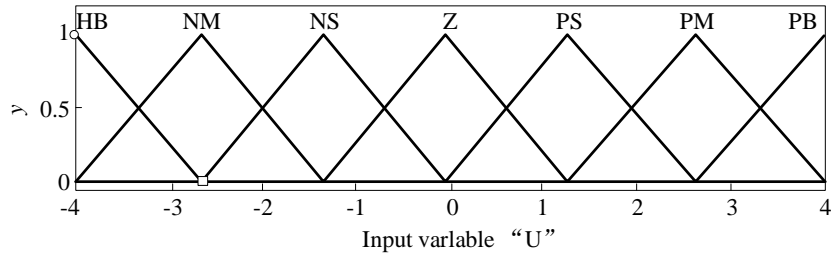

(c) The membership function of the incremental $U$ of the controlled system an example of a fuzzy controller.

The characteristics and factors of the input/output variables are selected. For this fuzzy controller, the domain of the input variable, according to the experience of the expert, should be "PB" for the maximum value of the language if the value of the system deviation $E$ is more than or equal to $20 \mathrm{~lx}$. The value of $E$ is less than or equal to $20 \mathrm{~lx}$, which is "NB". Therefore, the range of $E$ is $[-20,20]$, and the fuzzy set theory domain is $[-5,5]$. The value where $\theta$ represents the offset value of the output layer (or node). The trainer of the BP neural network is based on the process of error back propagation and correction, and it defines the total error function of the actual output $b_{p}$ of the $h$ sample pattern. The expected output mass is $E$, as shown as follows:

$$
E=\sum_{p=1}^{h}\left(b_{p}-b_{p}\right)^{2} / 2
$$

\section{RESULT ANALYSIS AND DISCUSSION}

\subsection{Research on fuzzy feedback controller}

The input/output variable of the feedback controller is determined. In this design, the feedback controller is a two-dimensional fuzzy controller, that is, the double input and output mode. The input variables are the illuminance deviation $E$ and the deviation rate Ec. The output is the controlled system increment. This method not only can ensure the stability of the control system but also reduce overshoot and vibration. The membership function $M$ for the input/output variable is determined. A membership function is a fuzzy set that should be applied to address practical problems. Accurate construction of membership functions can lead to the full usage of the key of fuzzy sets. The triangular membership function is used in the system, and the MATLAB fuzzy toolbox is used to identify the GUI function editor. Fig. 2 shows of the quantizing factor $\mathrm{Ke}$ is 0.25 . Generally, $E$ of fuzzy controller input variables is not equal to the range of deviation in the system operation. A limiter should be added in the actual control to ensure that the error is within the allowed range.

Similarly, the domain and the controller output and error variation factors can be determined according to the standards of illumination design for civil buildings, the illumination principle of indoor working lighting system, and the international vision ergonomics principle. The standard illumination value is $420 \mathrm{~lx}$, and the luminance area of the luminaire is set to $[300,500]$. Therefore, the ratio factor $K u$ of the controller output should be 5 . Moreover, error changes must be set according to the actual requirements, where KEC is equal to 0.01 in this controller.

In the actual control, the continuous domain should be discrete. For example, the fuzzy set theory domain of $E$ error is divided into seven grades, and each grade corresponds to a fuzzy subset. That is $\{-5,-4,-3,-2,-1,0,1,2,3,4,5\}$ correspond to (NB, NM, NS, ZO, PS, ZO). Then, the elements in the domain were determined and the membership degrees of the fuzzy linguistic variables are identified.

The fuzzy control rule is the core of fuzzy controller, reflecting the knowledge collection of a particular control problem. In the formulation of the fuzzy rules, the following requirements should be met. For the perceptibility, the fuzzy control model should constantly be able to obtain a suitable control function for the each reasoning of process state. 


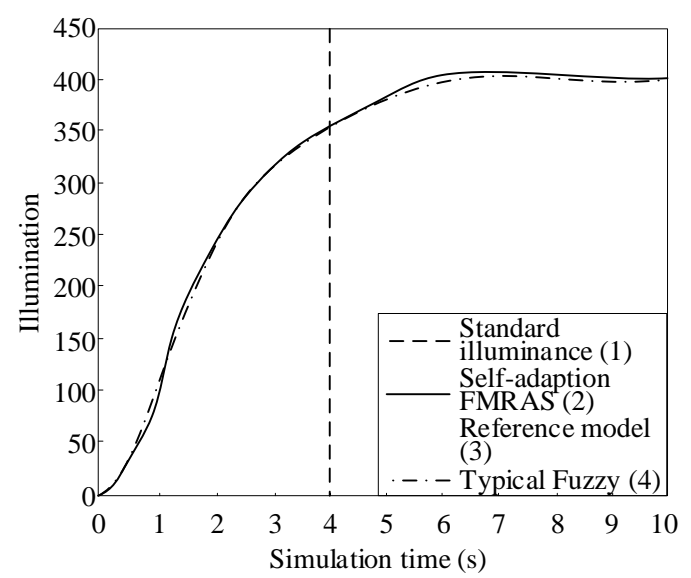

(a) First order contrast diagram

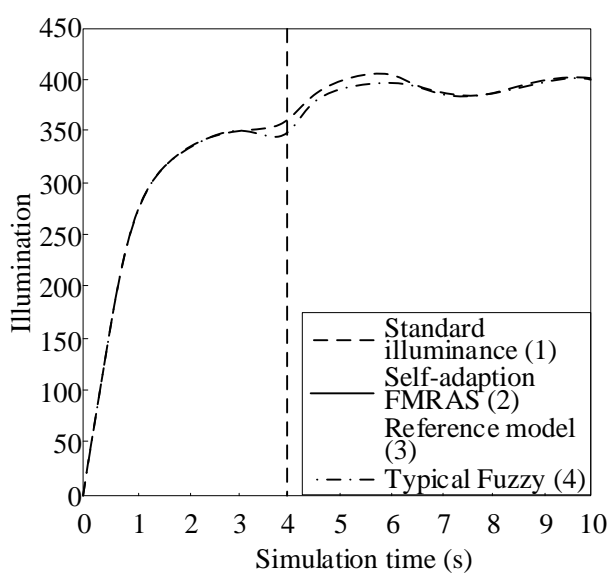

(b) Two order contrast diagram

Fig.3. Improved adaptive simulation results

This characteristic is called "completeness," which indicates that a runaway situation does not exist for the number of fuzzy control rules. If the input of a fuzzy controller has $m$, the numbers of fuzzy classifiers for each input are $n 1, n 2, \ldots, n m$; and the maximum possible fuzzy rule number is $\operatorname{Nmax}=\mathrm{n} 1$, $\mathrm{n} 2, \ldots, \mathrm{nm}$. The actual number of the fuzzy control numbers depends on many factors. The general principle is to minimize the number of rules to simplify the design and implementation of fuzzy controllers.

In lighting control, the illumination value is mainly affected by natural light. When natural lighting is high, the lamps in the classroom must be closed. Meanwhile, when natural lighting is low, the lamps and lanterns in the classroom must be opened, and the standard value of illumination is guaranteed. This study focuses on the actual lighting control. Fuzzy control table rules, combined with the actual situation and the experience of manual lighting control, can be obtained. The E, EC, and $U$ were the fuzzy linguistic variables of illumination deviation e, deviation rate $E C$, and output $u$, respectively. This table represents control rules, such as if ( $E$ is $\mathrm{NB})$ and (EC is NB), then ( $U$ is PB)). Practically, the result must be transformed into a fuzzy control response table. The method of the fuzzy logic control is used to calculate all the input languages $M$ $(E, E C)$ after quantization and calculate the output table generated by the fuzzy controller of each state. The method is placed in the computer in the form of "file." When a real-time control is performed, determining the control strategy from the file based on the input information is convenient. The fuzzy inference method is used as follows. First, the fuzzy relation $R$ is obtained. Then, the fuzzy output is ob- tained using the synthetic reasoning method according to the input deviation and the variation rate of the deviation. Finally, the fuzzy quantity is transformed to the exact quantity via anti-fuzzification. Thus, the design of the fuzzy feedback controller is complete.

\subsection{Simulation and Analysis}

The step size is set, and simulation is performed. This simulation compares the classical fuzzy control with the improved adaptive FMRAS to verify the progressiveness and experimentation of the improved model and ensure that the control rules and quantization factors of the input/output variables are the same. The results are shown in Fig. 3. Fig. 3(a) presents the result of the performance comparison between the improved adaptive FMRAS and classical fuzzy control in the first-order system. Fig. 3(b) shows the comparison of the performance results of the improved adaptive FMRAS and the classical fuzzy control under the two-order system.

As shown in the figures, in comparison with the typical fuzzy controllers commonly used at present, the adaptive FMRAS has the following advantages: good tracking performance, high steady-state accuracy, small overshoot, and high response speed. It can meet the illumination requirement of the bridge and achieve the design goal.

\section{CONCLUSION}

Designs of urban landscape bridge lighting are the growing concern of the public. Night landscape lighting project is important regardless of the structural design and implementation. ZigBee techno- 
logies, such as embedded ARM, sensor, and other lighting systems, are combined to design a city landscape bridge lighting control system. Through the evaluation of eight two-level, 24 three-level, and five four-grade indexes on the basis of three aspects, namely, design process, electricity consumption calculation, and lighting effect, the hierarchy framework and index relationship of the entire system are clearly defined. Many angles reflect the links involved in the design of bridge lighting system, providing an omni bearing indicator specimen for establishing the evaluation system of the bridge lighting system. The neural network is used to validate the screening results. The information is processed on the basis of the knowledge and experience of the experts, and the subjective impact and uncertainty of human weighting can be reduced.

\section{ACKNOWLEDGEMENT}

Fund Project: Fund Project of National Science Foundation of China (51208054), Special Fund Project of Fundamental Research Fees of Central Collages

\section{REFERENCES:}

1. Hale J D, Davies G, Fairbrass A J, et al. Mapping lightscapes: spatial patterning of artificial lighting in an urban landscape. PloS one, 2013. V8, \#5, p.61460.
2. Haiying Li, Xian Li, Xinyue Xu, Jun Liu, Bin Ran. Modelling departure time choice of metro passengers with a smart corrected mixed logit model - A case study in Beijing. Transport Policy. 2018, \#69, pp.106-121.

3. Johansson E, Emmanuel R. The influence of urban design on outdoor thermal comfort in the hot, humid city of Colombo, Sri Lanka. International journal of biometeorology, 2006. V51, \#2, pp.119-133.

4. Hayden D. Urban Landscape History. The People, Place, and Space Reader, 2014, p.82.

5. Lee Y C, Ahern J, Yeh C T. Ecosystem services in peri-urban landscapes: The effects of agricultural landscape change on ecosystem services in Taiwan's western coastal plain. Landscape and Urban Planning, 2015. V139, pp.137-148.

6. Gaston K J, Davies T W, Bennie J, et al. Reducing the ecological consequences of night-time light pollution: options and developments. Journal of Applied Ecology, 2012. V49, \#6, pp.1256-1266.

7. Wuren G, Yang X, Xia J. To Explore the Urban Landscape Lighting Development in China - Taking the City of Shanghai as an Example. Acta Oeconomica, 2015. V65, \#s2, pp.251-265.

8. Garrido-Jiménez F J, Magrinyá F, del Moral-Ávila M C, et al. The Relationship Between Urban Morphology and Street Lighting Operating Costs: Evidence from Medium-sized Spanish Cities. Applied Spatial Analysis and Policy, 2017. V10, \#3, pp.381-399.

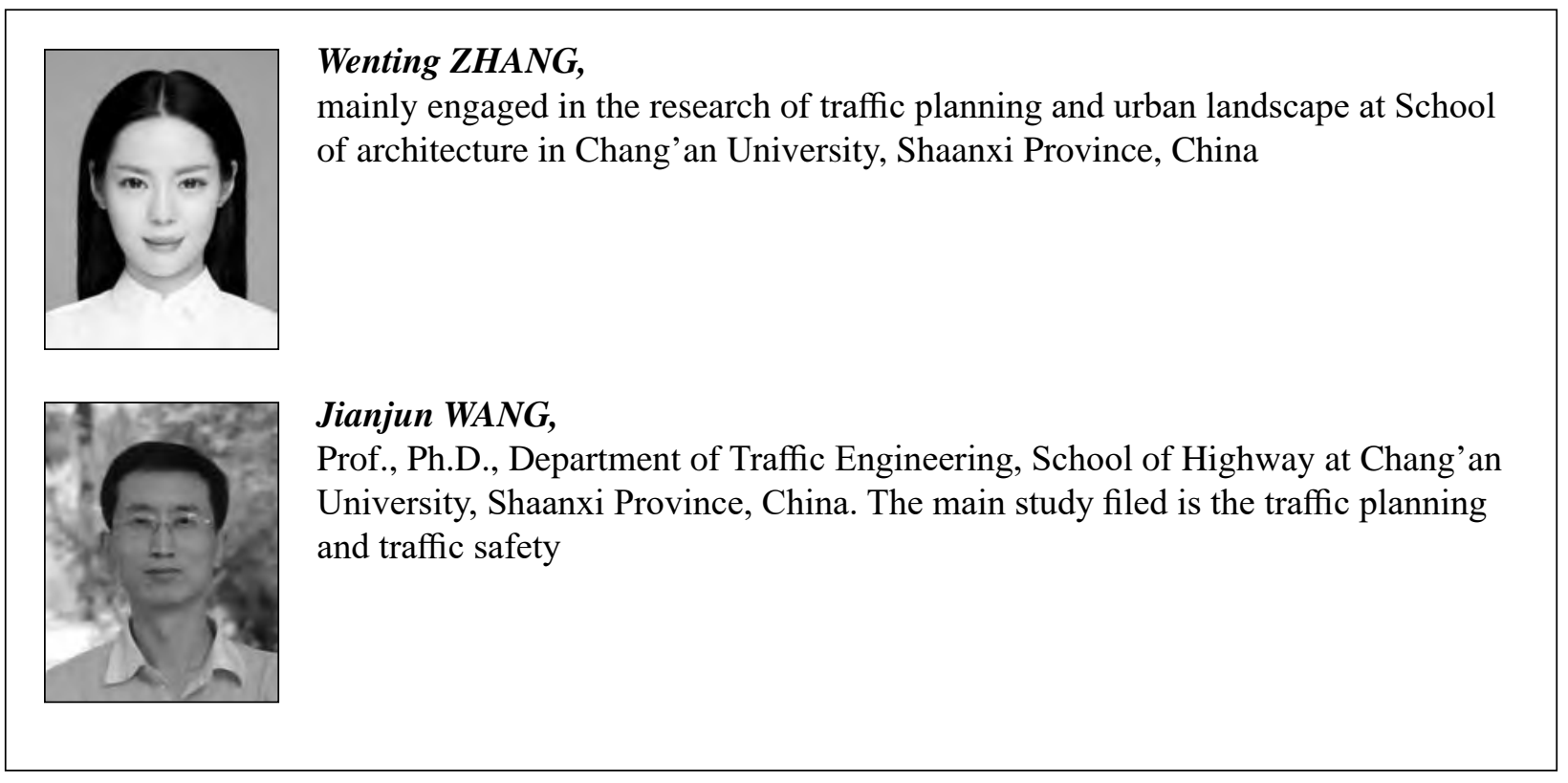

